\title{
Prevalence and risk factors of post- traumatic stress disorder among elderly survivors six months after the 2008 Wenchuan earthquake in China
}

\author{
Lan Li ${ }^{1,2,3}$, Jan D. Reinhardt ${ }^{3,4,5}$, Craig Van Dyke ${ }^{1,6}$, Heng Wang ${ }^{7}$, Maoqiong Liu ${ }^{8}$, Aiko Yamamoto9 \\ Qian Chen ${ }^{10^{*}}$ and Xiuying $\mathrm{Hu}^{11^{*}}$
}

\begin{abstract}
Background: Several studies indicate that older age is a risk factor for probable post-traumatic stress disorder (PTSD). However, evidence on the prevalence and risk factors for elderly disaster survivors is limited.

Methods: Multi-stage stratified sampling was applied in this cross-sectional study. The Revised Version of the Impact of Event Scale (IES-R) was used to evaluate symptoms of PTSD. Chi-squared test was used for univariable analysis of prevalence of probable PTSD by possible determinants. Multivariable logistic regression analysis was utilized to further explore risk factors for PTSD.

Results: 427 elderly survivors age 60 or older participated. The prevalence of probable PTSD was 40.5, 36.3, and $21.5 \%$ according to a cut off score of the IES-R of 33, 35, and 2 points on average across items, respectively. In multivariable logistic regression, elderly survivors with a higher number of diagnosed chronic illnesses were more likely to be screened positive for PTSD and those with a greater number of family members living in the same home were less likely to be classified as having probable PTSD for all cut off scores. Elderly survivors with improved economic status and those with primary school or lower education were more often estimated to have probable PTSD with a cut off score of 35 and 2 points on average.

Conclusions: Elderly survivors in a high impact area following a major earthquake are at high risk for developing PTSD. Those who live alone and report pre-existing chronic illness are particularly vulnerable.
\end{abstract}

Keywords: post-traumatic stress disorder, elderly, disaster, earthquake

\section{Background}

Post-traumatic stress disorder (PTSD) is the most frequently reported mental disorder following disasters $[1,2]$ and was a major problem after the 2008 Wenchuan earthquake. A meta-analysis from 2016 by Dai and colleagues indicated that the pooled prevalence of PTSD from 46 studies of 16 earthquakes from eleven countries

\footnotetext{
*Correspondence: hxqianchen@126.com; huxiuying@scu.edu.cn

${ }^{10}$ Center of Gerontology and Geriatrics, National Clinical Research Center of Geriatrics, West China Hospital, Sichuan University, No. 37 Guoxue Xiang, Chengdu 610041, Sichuan Province, China

${ }^{11}$ Innovation Center for Nursing Research, West China School of Medicine/ West China Hospital, Sichuan University, No. 37 Guoxue Xiang, Chengdu 610041, Sichuan Province, China

Full list of author information is available at the end of the article
}

including 25 studies from the Wenchuan earthquake was $28.8 \%$ at 9 months or earlier and $19.5 \%$ after 9 months [3]. A recent systematic review of 58 studies of PTSD after the Wenchuan earthquake included 15 community studies on the prevalence of PTSD in the general population. Prevalence in the most severely impacted areas ranged from 86.2\% in Mianzhu city at 1-2 months after the disaster to 8.0\% in Yongang and Guangji township at 44 months after the earthquake. This reflects a pattern of declining prevalence of PTSD over time [4]. The same review also reported that being female, having lower education, being married, being middle-aged and older were demographic risk factors, while being trapped, suffering an injury, witnessing people dying, losing loved ones, and experiencing

(c) The Author(s). 2020 Open Access This article is distributed under the terms of the Creative Commons Attribution 4.0 International License (http://creativecommons.org/licenses/by/4.0/), which permits unrestricted use, distribution, and 
extreme fear during the disaster were additional risk factors. Feelings of guilt and low social support may also be associated with an increased risk of developing PTSD [3-5].

Older persons are particularly vulnerable to the adverse effects of disasters such as earthquakes. They may be at higher risk because of an accumulation of personal losses, decreased cognitive capacity, chronic illnesses, physical disability, social isolation, poor financial circumstances, limited access to resources, and communication difficulties in using modern technologies [6]. These chronic stressors may severely compromise psychological coping mechanisms, trigger memories of earlier traumatic experiences [7], and place the elderly at high risk for being emotionally overwhelmed following a destructive earthquake.

Previous research on PTSD after the Wenchuan earthquake focused on child and adolescent, community dwelling elderly survivors, and rescue workers. Huang and colleagues [8] surveyed 470 Wenchuan earthquake survivors residing in the community aged 60 years or older from three different areas, namely severely impacted $(n=$ 101), moderately impacted $(n=153)$, and mildly impacted $(n=197)$ at 6 months after the disaster. They reported an overall PTSD prevalence of $32.9 \%$ with local prevalence estimates ranging from $56.3 \%$ in the severely impacted area to $25.6 \%$ in the moderately impacted area. They identified the following risk factors: belonging to an ethnic minority for the severely impacted area; being female and having experienced extreme fear during the earthquake for the moderately impacted area; and having a lower education level, having experienced fear during the earthquake, being religious, and having been injured or trapped for the mildly impacted area. Zhang and colleagues [9] conducted a community-based study including 284 survivors aged 60 years or older from severely impacted areas 1 year after the Wenchuan earthquake. They reported a prevalence of PTSD of $26.3 \%$ assessed with the PTSD Checklist. Loss of livelihood and initial level of fear were risk factors for PTSD among study participants. In addition, a study of 713 military veterans aged 60 years or older residing in the community of a general disaster affected area 2 years after Wenchuan earthquake found a PTSD prevalence of $3.09 \%$ as assessed with the PTSD Checklist. The incidence of angina, arrhythmia, hypertension, functional dyspepsia and sleep disorders was higher in elderly earthquake survivors with PTSD [10]. Another study reported a prevalence of $22.65 \%$ assessed with PTSD Scale for the Diagnostic and Statistical Manual of Mental Disorders in 287 Qiang citizens aged 60 years and older 3 years after the Wenchuan earthquake. They found the following risk factors for developing PTSD: being female, being widowed, having lower level of education, having lower monthly income, suffering an injury, being bereaved, and having lower level of social support [11].
Prior studies of PTSD prevalence and associated risk factors in the elderly following the Wenchuan earthquake have two limitations. Only one study was conducted about 6 months after the earthquake and sample sizes of elderly survivors from the severely impacted area were relatively small. Studying the prevalence and risk factors for developing PTSD in the elderly following natural disasters is important for several reasons. First, China has a rapidly aging population (National bureau of Statisics) with a 2017 estimate of 241 million people (17.3\% of the population) age 60 years or older, and projections are that the elderly population will double by 2050. Second, PTSD causes marked suffering in individuals and families. It limits their functional capacity and compromises a community's ability to recover from disasters [12, 13].

Our study aimed to: 1) estimate the prevalence of PTSD among elderly Wenchuan earthquake survivors in a severely impacted area at 6 months after the earthquake based on a representative sample, and 2) to determine possible risk factors within this population.

\section{Methods \\ Design}

This was a cross-sectional study conducted 6 months (November 2008) after the earthquake.

\section{Setting}

An 8.0-magnitude earthquake occurred on May 12, 2008 in Wenchuan County of Sichuan Province, China. According to the Ministry of Civil Affairs, 69,227 people were confirmed dead, 374,643 injured, and an additional 17,923 were unaccounted for. Dujiangyan, a county-level prefecture and subdivision of Chengdu, was the fourth most severely impacted area in Sichuan Province. The intensity of the Wenchuan earthquake reached a peak of magnitude 9.0 on the Richter Scale and 3091 people were killed and another 141 were unaccounted for in this area [14]. On the basis of the disaster severity and impact, the State Council, divided the disaster area into most severely impacted areas (10 counties), severely impacted areas (41 counties), and general disaster areas (186 counties).

\section{Sample}

A multi-stage stratified sampling method was applied. First, two counties were selected at random from Dujiangyan prefecture. Next, two villages were randomly chosen from each of the previously selected counties. Finally, two communities (neighborhoods) were randomly selected within the two villages and all elderly survivors were aproached in these two communities. In the following, elderly persons were approached at central places of the respective communities. Participants were encouraged 
to recommend other elderly persons living in their community to participate in the study who were then approached by the research team, i.e. employing a snowball method.

\section{Participants}

Included were people aged 60 or older who lived in the selected communities, experienced the earthquake, and provided informed consent. Of 497 elderly survivors recruited for this study, 38 participants were excluded because they had difficulties understanding the questions. An additional 32 refused to participate. Thus, 427 participants completed the survey. The response rate was $85.9 \%$.

\section{Data Collection}

Two research assistants with master degrees in medical science were trained in the use of the IES-R and communication skills. The importance and purposes of this survey were explained to each participant, and they completed the scale based on the difficulty they experienced from the earthquake during the past 7 days. For those participants, who were unable to complete the questionnaire independently (e.g. limited literacy or physical illness) the research assistants read each question out loud, the participant answered verbally, and the assistants then registered their response on the questionnaire. After completion, data were checked for integrity.

\section{Variables}

\section{Outcome: Revised Version of the Impact of Event Scale (IES-R)}

The IES-R is commonly applied to evaluate symptoms of PTSD [15]. The scale includes 22 questions and has three dimensions: intrusion, numbness/avoidance and hyperarousal. Participants are required to rank the severity of a particular event over the past 7 days on a scale ranging from 0 to 4 (none, few, moderate, high, extremely high). The total score ranges from 0 to 88 . In China, a cut-off for IES-R has not been established for the general population or for a population of earthquake victims. The only study establishing a cut-off based on positive predictive value was conducted in a population of female offenders and the authors suggested a cut-off of 35 or 40 [16]. The comparability of the population examined in this research with our study population is, however, severely limited. No other studies using sensitivity, specificity, and/or positive predictive value of the Chinese IES-R to establish an optimal threshold exist to the best of our knowledge. While two studies on Wenchuan and Lushan earthquake victims used a cutoff of 35 based on the study of female offenders from Hunan women's prison in China, other studies conducted in Chinese earthquake victims used a cut-off of 33 or of an average of 2 points across items based on validation studies of the English IES-R. The cut off scores used in different studies on Wenchuan earthquake survivors are provided in Table 1 . In the present study, we provide results for cut offs of 33 and 35 total score as well as an average of 2 points across all scale items to assure optimal comparability with previous research.

While an optimal cut off has not yet been established, the IES-R is one of two screening instruments for PTSD (the other is the PTSD checklist - civilian version) that have been translated and validated in Chinese. The Chinese version of the IES-R demonstrated good reliability and convergent validity based on its correlation with the General Health Questionnaire-20 [31] and can be used to assess the impact of traumatic life events in the Chinese population. Cronbach's alpha reliability was reported as 0.890 in previous research [32]. In this survey, the value was 0.963 .

\section{Probable risk factors of PTSD}

Demographic variables assessed in this study included age, gender, marital status and educational level. Earthquake exposure related variables comprised: house damage, injuries to self and injury or death of family members (no injury vs. injury vs. death). Post-earthquake variables were change in economic status (worse than before, stayed the same, better than before); presence of chronic illnesses (Do you have one or more of the following health conditions? a) hypertension, b) diabetes, c) cerebral infarction, d) cancer, e) angina pectoris, f) asthma, or g) gout); and methods employed by the participants to evaluate their own health (How do you evaluate your own health? a) I regularly measure vital signs such as blood pressure, b) I regularly measure my weight, c) I regularly consult online resources and books about health issues, d) regularly visit Traditional Chinese Medicine doctors, and e) regular check ups at the hospital). The latter variable was supposed to indicate whether someone was more or less concerned about their overall health. Based on chronic illnesses reported, we created a sum index for the number of chronic illnesses for further analysis ranging from zero to seven. We also constructed a sum index for the number of methods employed by the study participants to evaluate their own health ranging from zero to five.

\section{Data Analysis}

Stata (version 14.0) was used for all analyses. Descriptive statistics for the sample are provided. For further analyses, participants were divided into two groups based on their IES-R scores according to different cut off scores (i.e. total score $\geq 33$, total score $\geq 35$, and average score across items $\geq 2$ ). Accordingly, the dependent variable was probable PTSD. Independent variables were age, gender, marital status, education level, house 
Table 1 Different cut off scores of IES-R used for estimation of prevalence of PTSD in Wenchuan and Lushan earthquake survivors

\begin{tabular}{|c|c|c|c|c|c|}
\hline Author (year) & Study population & Time point & $\begin{array}{l}\text { Cut off } \\
\text { score }\end{array}$ & Sample & Prevalence of PTSD \\
\hline Qu et al. [17] (2012) & New mothers & $\begin{array}{l}8 \text { months after } 2008 \\
\text { Wenchuan earthquake }\end{array}$ & 1.8 & 317 & $19.9 \%$ \\
\hline Guo et al. [18] (2018) & $\begin{array}{l}\text { Wenchuan Earthquake } \\
\text { Survivors }\end{array}$ & $\begin{array}{l}8 \text { years after } 2008 \\
\text { Wenchuan earthquake }\end{array}$ & 2.0 & 1369 & $11.8 \%$ \\
\hline Guo et al. [19] (2017) & Wenchuan earthquake victims & $\begin{array}{l}8 \text { years after } 2008 \\
\text { Wenchuan earthquake }\end{array}$ & 2.0 & 1369 & $11.8 \%$ \\
\hline Guo et al. [20] (2015) & Wenchuan earthquake victims & 6 months after event & 2.0 & 1362 & $22.1 \%$ \\
\hline Liu et al. [21] (2012) & Qiang Women & $\begin{array}{l}1 \text { year after Wenchuan } \\
\text { earthquake }\end{array}$ & 2.0 & 270 & $\begin{array}{l}\text { 37.0\%(intrusion subscale), } \\
26.3 \% \text { (avoidance subscale), } \\
\text { 32.6\%(hyperarousal subscale) } \\
\text { and } 8.5 \% \text { (all } 3 \text { subscales) }\end{array}$ \\
\hline Qu et al. [22] (2012) & Pregnant women & $\begin{array}{l}1.5 \text { years after Wenchuan } \\
\text { earthquake }\end{array}$ & 2.0 & 311 & $12.2 \%$ \\
\hline Chan et al. [23] (2011) & Adult survivors & $\begin{array}{l}7 \text { and } 8 \text { months after } \\
\text { Wenchuan earthquake }\end{array}$ & 2.0 & 243 & 55.6 and $26.4 \%$ \\
\hline
\end{tabular}

The cut off scores listed above describe average scores for each symptom/per symptom, whereas the ones below describe the overall summed score.

\begin{tabular}{|c|c|c|c|c|c|}
\hline Zhang et al. [24] (2011) & Adult survivors & $\begin{array}{l}2 \text { months after Wenchuan } \\
\text { earthquake }\end{array}$ & 33 & 512 & $82.6 \%$ \\
\hline Wang et al. [25] (2011) & Adult survivors & $\begin{array}{l}3 \text { months after the } 2008 \\
\text { Wenchuan earthquake }\end{array}$ & 33 & 3622 & $31.4 \%$ \\
\hline Wang et al. [26] (2010) & Health care workers & $\begin{array}{l}3 \text { months after Wenchuan } \\
\text { earthquake }\end{array}$ & 33 & 343 & $19.0 \%$ \\
\hline Xiuying Hu et al. [27] (2016) & Disaster-bereaved survivors & $\begin{array}{l}6 \text { months after Wenchuan } \\
\text { earthquake }\end{array}$ & 33 & 226 & $\begin{array}{l}38.9 \% \text { at } 6 \text { months and } \\
16.8 \% \text { at } 18 \text { months }\end{array}$ \\
\hline Ellen J. Schenk et al. [28] (2017) & Medical rescue workers & $\begin{array}{l}14 \text { months after Wenchuan } \\
\text { earthquake }\end{array}$ & 33 & 337 & $17.0 \%$ \\
\hline Chen et al. [29] (2015) & Elderly survivors & $\begin{array}{l}6 \text { months after Lushan } \\
\text { earthquake }\end{array}$ & 35 & 1509 & $5.2 \%$ \\
\hline Huang et al. [8] (2009) & Elderly survivors & $\begin{array}{l}6 \text { months after Wenchuan } \\
\text { earthquake }\end{array}$ & 35 & 470 & $32.9 \%$ \\
\hline Pan et al. [30] (2015) & Junior high school students & $\begin{array}{l}3 \text { years after Wenchuan } \\
\text { earthquake }\end{array}$ & 40 & 373 & $29.6 \%$ \\
\hline
\end{tabular}

damage, number of people living in the same home, number of chronic illnesses reported (0, 1, 2 and more), number of methods employed by participants to evaluate their own health $(0,1,2$ and more). Univariable analyses were based on chi-square tests. Multivariable analysis was based on multiple logistic regression analysis. All variables were included in the multivariable logistic model since we were interested in exploring an overall predictive model, rather than precisely estimating the effects of particular variables. Two-sided testing was used for all tests, and the significance level was set at $P<0.05$.

\section{Results}

The mean age of the participants was 70.0 years $(\mathrm{SD}=$ $7.2)$ ranging from 60 to 91 years, $53.9 \%(n=230)$ were male, $74 \%(n=316)$ were married, and $66.7 \%(n=285)$ had elementary school or a lower level of education. The prevalence of probable PTSD was 40.5, 36.3, and 21.5\% with a cut off score of 33, 35, and 2 points on average across items, respectively (Table 2 ).

Table 3 presents the results for univariable analysis of probable PTSD by demographics and other potential risk factors. People aged 80 years and older had a higher prevalence of PTSD. Moreover, study participants whose economic status improved had a higher prevalence of PTSD than those whose economic status did not change or became worse. Those living alone and those reporting a higher number of chronic illnesses showed a higher prevalence of probable PTSD. Conversely, those not using any methods to evaluate their own health had a lower prevalence of probable PTSD than those employing one or more such means. Though not significant, the prevalence of PTSD in women was estimated about three to $4 \%$ lower for cut off scores of 2 points per item and 33 points total score.

The results of the multiple logistic regression analysis with cut off scores of 2 on average, and total scores of 
Table 2 Mean IES-R scores and prevalence of suspected PTSD by different cut off scores of IES-R $(n=427)$

\begin{tabular}{llll}
\hline Variables & \multicolumn{2}{l}{ Probable PTSD according to IES-R n(\%) } & Cut off score average of 2 across items \\
\cline { 2 - 3 } & 33 cut off score & 35 cut off score & $92(21.5)$ \\
\hline Yes & $173(40.5)$ & $272(63.3)$ & $335(78.5)$ \\
No & $254(59.5)$ & & \\
IES-R & Mean \pm standard deviation & \\
Intrusion & $11.1 \pm 5.9$ & \\
Avoidance & $11.2 \pm 6.5$ & \\
Hyperarousal symptoms & $10.8 \pm 5.8$ & \\
Total score & $33.1 \pm 17.4$ & \\
\hline
\end{tabular}

33 and 35 are provided in Table 4 . In all models the odds for being classified as having probable PTSD were lower with an increasing number of persons living in the household and were higher with the number of chronic illnesses. In addition, economic status was a significant predictor of probable PTSD in the model featuring a cut off of 2 points on average across IES-R items, indicating that people whose economic status did not change or improved showed higher odds of probable PTSD. The same trend was observed for the other cut offs. The odds for being classified as having probable PTSD also were lower with increasing educational achievement in the model employing a cut off score of 35. Age, gender, marital status, house damage, having suffered an injury, having family members who were injured or died as well as the number of methods participants employed to evaluate their own health status did not play a major role when it was adjusted for other covariates.

\section{Discussion}

This research focused on the prevalence of PTSD and risk factors among elderly earthquake survivors from a severely impacted area 6 months after the Wenchuan earthquake. The prevalence of probable PTSD was high in this population. Participants with a higher number of self-reported chronic illnesses were more likely and those with a greater number of family members living in the same home were less likely to be screened positive for PTSD according to multivariable analysis, independent of the IES-R cut off score chosen. Elderly survivors with improved economic status and those with lower education level were more likely to be screened positive for PTSD in one of the models only. Differences in prevalence of probable PTSD by employing more methods to evaluate their own health were significant in univariable analysis only.

The prevalence of probable PTSD found in this study population when employing IES-R cut off scores of 33 or 35 was higher than the pooled prevalence reported in the meta-analysis on PTSD in earthquake survivors by Dai et al. [3] that indicated a pooled prevalence of probable PTSD of $28.8 \%$ at 9 months or earlier after earthquakes.

Since the prevalence of PTSD tends to decline with increasing time after earthquakes [3, 4], we focused our comparison on other studies that assessed PTSD prevalence 6 months after earthquakes. One previous study by Huang and associates reported the prevalence of probable PTSD in the elderly at 6 months after the Wenchuan earthquake, based on an IES-R cut off score of 35 [8]. The prevalence of probable PTSD reported by Huang et al. [8] for the severely impacted areas and the generally disaster affected area were about $10.0 \%$ lower than the prevalence reported in the present study. However, the prevalence for the most severely impacted area was about $20.0 \%$ higher than the prevalence found in the present study when using a cut off score of 35 . It should be noted, however, that the sampling method employed in the study by Huang and colleagues was not specified. One possible explanation for the differences may be that the elderly were from Beichuan county, Anxian county, Shifang city and Dujiangyan city while all the participants in the present study were from Dujiangyan, that is closer to the capital Chengdu city, thereby allowing greater availability of medical and government support. Chen and colleagues [29] reported a prevalence of $5.2 \%$ probable PTSD with a cut off score of 35 among 1509 elderly survivors at 6 months after the Lushan earthquake, another severe earthquake that occurred in Sichuan province in 2013. This is markedly lower than our finding. A possible explanation is that the Wenchuan earthquake (magnitude 8.0) was more destructive than the Lushan earthquake (magnitude 7.0). Moreover, Lushan earthquake survivors may have benefited from experiences with psychological relief and medical aid gained during the Wenchuan earthquake. The prevalence of probable PTSD based on an IES-R cut off of 2 points on average across items found in the present study was similar to the one reported in a study on adult Wenchuan earthquake survivors by Guo and colleagues [20] which was conducted in a similar area. The 6 months prevalence of PTSD when based on an IES$\mathrm{R}$ cut off score of 33 found in this study slightly exceeded 
Table 3 Univariable analysis of probable PTSD by potential risk factors among elderly survivors six months after the Wenchuan earthquake $(n=427)$

\begin{tabular}{|c|c|c|c|c|c|c|c|c|c|c|}
\hline \multirow[t]{2}{*}{ Variables } & \multirow[t]{2}{*}{ Subject, n(\%) } & \multicolumn{3}{|c|}{ Cut off score of 2 points on average } & \multicolumn{3}{|c|}{ Cut off score of 33 total score } & \multicolumn{3}{|c|}{ Cut off score of 35 total score } \\
\hline & & $\overline{\mathrm{n}(\%)}$ & $x^{2}$ & $P$ & $\overline{\mathrm{n}(\%)}$ & $x^{2}$ & $P$ & $\overline{\mathrm{n}(\%)}$ & $x^{2}$ & $P$ \\
\hline \multicolumn{11}{|l|}{ Age } \\
\hline $60-79$ & $376(88.1)$ & $77(20.5)$ & 2.115 & 0.146 & 149 (39.6) & 1.027 & 0.311 & $135(35.9)$ & 0.212 & 0.645 \\
\hline$\geq 80$ & $51(11.9)$ & $15(29.4)$ & & & $24(47.1)$ & & & $20(39.2)$ & & \\
\hline \multicolumn{11}{|l|}{ Gender } \\
\hline Male & $230(53.9)$ & $46(20.0)$ & 0.703 & 0.402 & $89(38.7)$ & 0.683 & 0.408 & $83(36.1)$ & 0.010 & 0.921 \\
\hline Female & $197(46.1)$ & $46(23.4)$ & & & $84(42.6)$ & & & $72(36.5)$ & & \\
\hline \multicolumn{11}{|l|}{ Marital status } \\
\hline Never married/divorced & $14(3.3)$ & $2(14.3)$ & 1.104 & 0.576 & $3(21.4)$ & 2.252 & 0.324 & $3(21.4)$ & 1.413 & 0.493 \\
\hline Widowed & $97(22.7)$ & $24(24.7)$ & & & $41(42.3)$ & & & $35(36.1)$ & & \\
\hline Married & $316(74.0)$ & $66(20.9)$ & & & $129(40.8)$ & & & $117(37.0)$ & & \\
\hline \multicolumn{11}{|l|}{ Education level } \\
\hline Elementary school or lower & $285(66.7)$ & $69(24.2)$ & 3.797 & 0.051 & $124(43.5)$ & 3.340 & 0.068 & $114(40.0)$ & 5.059 & 0.024 \\
\hline Middle school & $131(30.7)$ & $22(16.8)$ & & & $46(35.1)$ & & & $38(29.0)$ & & \\
\hline Senior high school or higher & $11(2.6)$ & $1(9.1)$ & & & $3(27.3)$ & & & $3(27.3)$ & & \\
\hline \multicolumn{11}{|l|}{ Suffered own injury } \\
\hline No injury & $378(88.5)$ & $82(21.7)$ & 0.042 & 0.837 & $150(39.7)$ & 0.945 & 0.331 & $135(35.7)$ & 0.487 & 0.485 \\
\hline Injury & $49(11.5)$ & $10(20.4)$ & & & $23(46.9)$ & & & $20(40.8)$ & & \\
\hline \multicolumn{11}{|l|}{ Family members injured } \\
\hline No injury & $352(82.4)$ & $81(23.0)$ & 2.768 & 0.096 & $143(40.6)$ & 0.008 & 0.928 & $131(37.2)$ & 0.707 & 0.401 \\
\hline Injury & $38(8.9)$ & $7(18.4)$ & & & $15(39.5)$ & & & $12(31.6)$ & & \\
\hline Death & $37(8.7)$ & $4(10.8)$ & & & $15(40.5)$ & & & $12(32.4)$ & & \\
\hline \multicolumn{11}{|l|}{ House damage } \\
\hline Slightly & $84(19.7)$ & $17(20.2)$ & 0.106 & 0.745 & $28(33.3)$ & 2.233 & 0.135 & $28(33.3)$ & 0.397 & 0.529 \\
\hline Almost completely & $343(80.3)$ & $75(21.9)$ & & & $145(42.3)$ & & & $127(37.0)$ & & \\
\hline \multicolumn{11}{|l|}{ Change in economic status } \\
\hline Improved & $12(2.8)$ & $7(58.3)$ & 0.036 & 0.849 & $8(66.7)$ & 3.907 & 0.048 & $8(66.7)$ & 2.407 & 0.121 \\
\hline No change & $228(53.4)$ & $43(18.9)$ & & & 77 (33.8) & & & $69(30.3)$ & & \\
\hline Declined & $187(43.8)$ & $42(22.5)$ & & & $88(47.1)$ & & & $78(41.7)$ & & \\
\hline \multicolumn{11}{|c|}{ Number of family members living in the same home } \\
\hline 0 & $151(35.4)$ & $49(32.5)$ & 16.38 & $<0.001$ & $76(50.3)$ & 10.210 & 0.001 & $69(45.7)$ & 10.271 & 0.001 \\
\hline 1 & $113(26.5)$ & $21(18.6)$ & & & $44(38.9)$ & & & $40(35.4)$ & & \\
\hline$\geq 2$ & $163(38.2)$ & $22(13.5)$ & & & $53(32.5)$ & & & $46(28.2)$ & & \\
\hline \multicolumn{11}{|c|}{ Available measures to assess own health } \\
\hline 0 & $134(31.4)$ & $17(12.7)$ & 9.336 & 0.002 & $42(31.3)$ & 9.246 & 0.002 & $36(26.9)$ & 9.168 & 0.002 \\
\hline 1 & $246(57.6)$ & $61(24.8)$ & & & $105(42.7)$ & & & $96(39.0)$ & & \\
\hline$\geq 2$ & $47(11.0)$ & $14(29.8)$ & & & $26(55.3)$ & & & $23(48.9)$ & & \\
\hline \multicolumn{11}{|l|}{ Chronic illnesses diagnosed } \\
\hline 0 & $224(52.5)$ & $29(12.9)$ & 19.939 & $<0.001$ & $64(28.5)$ & 29.490 & $<0.001$ & $56(25.0)$ & 25.338 & $<0.001$ \\
\hline 1 & $133(31.2)$ & 40 (30.1) & & & $67(50.4)$ & & & $63(47.4)$ & & \\
\hline$\geq 2$ & $70(16.4)$ & 23 (32.9) & & & $42(60.0)$ & & & $36(51.4)$ & & \\
\hline
\end{tabular}


Table 4 Multivariable analysis of potential risk factors for probable PTSD for different IES-R cut off scores among elderly survivors six months after the Wenchuan earthquake $(n=427)$

\begin{tabular}{|c|c|c|c|c|c|c|c|c|c|c|c|c|}
\hline \multirow[t]{3}{*}{ Variables } & \multicolumn{4}{|c|}{$\begin{array}{l}\text { Cut off score of } 2 \text { points on } \\
\text { average }\end{array}$} & \multicolumn{4}{|c|}{ Cut off score of 33 total score } & \multicolumn{4}{|c|}{$\begin{array}{l}\text { Cut off score of } 35 \text { total } \\
\text { score }\end{array}$} \\
\hline & \multirow[t]{2}{*}{ OR } & \multirow[t]{2}{*}{$P$} & \multicolumn{2}{|c|}{$95 \% \mathrm{Cl}$ for OR } & \multirow[t]{2}{*}{ OR } & \multirow[t]{2}{*}{$P$} & \multicolumn{2}{|c|}{$95 \% \mathrm{Cl}$ for $\mathrm{OR}$} & \multirow[t]{2}{*}{ OR } & \multirow[t]{2}{*}{ P } & \multicolumn{2}{|c|}{$95 \% \mathrm{Cl}$ for OR } \\
\hline & & & Lower & Upper & & & Lower & Upper & & & Lower & Upper \\
\hline Age & 1.5 & 0.271 & 0.7 & 3.2 & 1.5 & 0.245 & 0.8 & 2.9 & 1.2 & 0.678 & 0.6 & 2.3 \\
\hline Gender & 1.1 & 0.809 & 0.6 & 1.8 & 1.1 & 0.598 & 0.7 & 1.8 & 0.9 & 0.816 & 0.6 & 1.5 \\
\hline Marital status & 1.2 & 0.612 & 0.6 & 2.3 & 1.4 & 0.191 & 0.8 & 2.5 & 1.4 & 0.219 & 0.8 & 2.5 \\
\hline \multicolumn{13}{|l|}{ Education level (reference: elementary school or lower) } \\
\hline Middle school & 0.6 & 0.073 & 0.3 & 1.1 & 0.7 & 0.095 & 0.4 & 1.1 & 0.5 & 0.012 & 0.3 & 0.9 \\
\hline Senior high school or higher & 0.3 & 0.324 & 0.04 & 2.9 & 0.5 & 0.314 & 0.1 & 2.0 & 0.5 & 0.361 & 0.1 & 2.1 \\
\hline \multicolumn{13}{|l|}{ Change in economic status (reference: improved) } \\
\hline No change & 0.2 & 0.022 & 0.1 & 0.8 & 0.3 & 0.082 & 0.1 & 1.2 & 0.3 & 0.074 & 0.1 & 1.1 \\
\hline Declined & 0.2 & 0.029 & 0.1 & 0.9 & 0.5 & 0.261 & 0.1 & 1.8 & 0.4 & 0.198 & 0.1 & 1.6 \\
\hline House damage & 1.2 & 0.572 & 0.6 & 2.3 & 1.5 & 0.134 & 0.9 & 2.6 & 1.2 & 0.523 & 0.7 & 2.1 \\
\hline Suffered own injury & 0.9 & 0.848 & 0.4 & 2 & 1.3 & 0.460 & 0.7 & 2.4 & 1.2 & 0.551 & 0.6 & 2.3 \\
\hline \multicolumn{13}{|l|}{ Family members injured (reference: no injury) } \\
\hline Injury & 0.8 & 0.657 & 0.3 & 2 & 0.9 & 0.730 & 0.4 & 1.9 & 0.7 & 0.352 & 0.3 & 1.5 \\
\hline Death & 0.4 & 0.116 & 0.1 & 1.2 & 0.9 & 0.741 & 0.4 & 1.8 & 0.7 & 0.383 & 0.3 & 1.5 \\
\hline Number of family members living in the same home & 0.6 & 0.005 & 0.5 & 0.9 & 0.7 & 0.019 & 0.6 & 1.0 & 0.8 & 0.032 & 0.6 & 1.0 \\
\hline Chronic illnesses diagnosed & 1.8 & 0.001 & 1.3 & 2.5 & 1.9 & $<0.001$ & 1.4 & 2.5 & 1.8 & $<0.001$ & 1.3 & 2.4 \\
\hline Available measures to assess own health & 1.4 & 0.096 & 0.9 & 2.2 & 1.4 & 0.077 & 1 & 2 & 1.4 & 0.055 & 1.0 & 2.1 \\
\hline Constant & 0.3 & 0.269 & $<0.01$ & 2.5 & 0.2 & 0.15 & $<0.001$ & 1.7 & 0.4 & 0.30 & 0.1 & 2.7 \\
\hline
\end{tabular}

the $38.9 \%$ prevalence reported at 6 months for a sample of 226 survivors whose family members had died in the earthquake [27]. However, the mean age of the participants in the former study was more than twenty years younger than our population.

Elderly survivors with more family members living in the same home had a lower prevalence of suspected PTSD in the present study. This result has not been explored in other studies but may reflect the beneficial effects of social support. Higher social support not only allows a greater opportunity to have contact with family members, friends, neighbors and other people, but also to get more resources from the household, community, society and the government. All these factors may help elderly survivors adapt to the changes in the environment caused by earthquakes. Elderly survivors with a high level of social support also tend to use more effective coping strategies than those with a lower level [33]. Elderly survivors with a higher number of family members living in the same home may not have experienced the earthquake alone. The feeling of fear and helplessness may thus be decreased. In line with the above considerations, intense fear was associated with less protective action to solve mental health problems [34] and increased traumatic stress symptoms following disaster in previous studies $[35,36]$. Elderly survivors, who screen positive for suspected PTSD, and are living alone should be prioritized for receiving mental health service.

The result that female participants did not show a higher prevalence of probable PTSD was different from previous research. Chen and colleagues [11] found an association between being female and PTSD in 287 Qiang citizens aged 60 years and older 3 years after the Wenchuan earthquake. Being female was also a predictor of suspected PTSD in 360 participants, aged 18 years or older 3 years after the Wenchuan Earthquake [37]. Moreover, women were more affected by PTSD among 512 high school students 10 months after the L'Aquila 2009 earthquake in Italy [38].

Our finding that elderly earthquake survivors with a greater number of chronic illnesses were more likely to be screened positive for PTSD had not been reported previously. However, it has been demonstrated that the presence of chronic illnesses and the number of chronic illnesses can be associated with PTSD in non-disaster affected populations [39]. Another study from the Wenchuan earthquake also showed that the incidence of angina, arrhythmia, hypertension, functional dyspepsia and sleep disorders was higher in survivors with PTSD than in those without PTSD among elderly survivors 2 years after the disaster [10]. In the group of patients suffering from chronic disease, the hardship of a chronic 
disease itself, may contribute to a state of PTSD [40]. On the other hand, PTSD may contribute to the development of chronic physical conditions, e.g. by affecting lifestyles. Families, local health institutions and community leaders should be prepared for disasters to ensure that mental health treatment capacity is quickly resumed in disaster situations. Elderly disaster survivors with chronic medical conditions should be a priority target group for PTSD screening and treatment.

Surprisingly, Improvement in economic status was associated with an increase in suspected PTSD among elderly survivors in this research. This finding differs from prior studies. A meta-analysis of 37 studies with a total of 56,722 participants found that adult survivors with lower socio-economic status were more likely to suffer from PTSD after earthquakes [41]. Lower income [42] or economic hardship [43] was also related to a higher risk of psychological distress among survivors after the Great East Japan Earthquake. The current finding that the perception of improvement in economic status was associated with increased odds of probable PTSD is difficult to explain and the small number of survivors who indicated an increase in economic status leads us to interpret this result with caution. A study by $\mathrm{Xu}$ and colleagues showed that survivors with a higher monthly income were more likely to seek mental health services after the Wenchuan earthquake [44]. Accordingly, it is possible that those survivors were more aware of their symptoms. Moreover, it is also possible that those who received larger subsidies immediately after the earthquake were more severely affected by disaster-related stressors and had greater losses [45].

A trend for low educational level being associated with a higher prevalence of suspected PTSD among elderly survivors was observed in all models used in this study. This is consistent with previous research from the Wenchuan as well as 1999 Taiwan earthquake. A metaanalysis of predictors for PTSD in adult survivors after Wenchuan earthquake found that low educational level was a predictor of suspected PTSD in 30 of 37 studies that included this predictor [41]. Low education was associated with higher odds of PTSD among survivors from the general population both in the short- as well as long-term after the Wenchuan earthquake [46, 47]. Two other studies on elderly survivors of the Wenchuan earthquake also demonstrated that those having lower levels of education were more likely to develop suspected PTSD at 6 months [8] and 36 months after the disaster [11]. A possible explanation of this finding is that elderly survivors with higher educational level have more medical resources and information resources at their disposal and have a better economic status. Accordingly, they may be able to mobilize more resources and employ more successful strategies and thus be more resilient to the development of PTSD. As a result, elderly survivors with lower educational level should be particularly targeted after earthquakes in severely hit disaster areas. PTSD screening and mental health services from local hospitals should be given priority for them. In addition, family members should be made aware of how to recognize the symptoms of PTSD and should be included in the delivery of mental health services.

\section{Limitations}

There are limitations to our study. First, the data was collected with a self-reported questionnaire that may have biased the results. The IES-R is a screening tool and cannot replace a diagnosis based on a systematic interview by a mental health professional. Second, no formal IES-R cut off score for PTSD has been established for a Chinese population. Accordingly, the prevalence of PTSD may have been over or underestimated. Third, baseline information on physical and mental health conditions in the population before the earthquake was not available so that excess morbidity in terms of PTSD due to the earthquake cannot be correctly determined. Fourth, since a control sample from a mildly or not affected area was not available, it is difficult to draw firm conclusions regarding of the effect of the earthquake on elevated prevalence of PTSD in elderly survivors. Fifth, although the sampling design was a multistage stratified design, we were unable to incorporate the strata into the analyses due to data restrictions. Sixth, as this study was conducted in a very severely impacted disaster area and the sample size was small, results may not be generalized to less severely impacted areas. Seventh, the small sample size may also result in low power to detect effects and imprecision in the estimation of confidence intervals.

\section{Conclusions}

Our findings suggest that elderly survivors in high impact areas have a high prevalence of PTSD following an earthquake. This is particularly true for those living alone and suffering from chronic medical conditions. Both of these factors will become more prominent over time. The Chinese elderly population grows and takes up a larger portion of the general population and there are fewer young people around to live with them and care for them, in part due to the several decades long one child policy [48]. These two factors also interact in that chronic medical conditions not only require greater care but they also create functional disabilities. Fewer young people around means these people get worse care for their medical conditions but there are also fewer people to assist them in overcoming the barriers and obstacles that are present in a damaged environment, especially following a disaster [49]. Following an earthquake, this population warrants systematic screening for PTSD to identify symptomatic individuals for referral to mental health services. 


\section{Abbreviations}

IES-R: Revised Version of the Impact of Event Scale; PTSD: Post-traumatic stress disorder

\section{Acknowledgements}

We extend grateful thanks to all the participants from extremely severe disaster area of Wenchuan earthquake and the nurses from Dujiangyan Second People's Hospital.

\section{Authors' contributions}

This study was designed by XH and AY. Data were collected by QC, HW and $\mathrm{ML}$. Data were analyzed by $\mathrm{LL}$ and JR. Data were interpreted by $\mathrm{LL}$, JR, and $C D$. $L L$ wrote the first draft. All other authors revised the manuscript for critical content. All authors have read and approved the submitted version of the manuscript.

\section{Funding}

This work was supported by the National Natural Science Foundation of China (Grant No.71871147), the Department of Science and Technology Research Projects of the Sichuan Province of China (Grant No.20185Z0404) and Graduate Student's Research and Innovation Fund of Sichuan University (2018YJSY103)

\section{Availability of data and materials}

The data of this survey is available from the corresponding author (Xiuying $\mathrm{Hu}$ ) upon reasonable request.

\section{Ethics approval and consent to participate}

Ethical approval to conduct this study was obtained from the West China Hospital Ethics Committee at Sichuan University (Sichuan,China). All participants and their families were educated about the goals and data collection procedures for this survey before written consent was obtained. Each participant could withdraw from the survey at any time or refuse to cooperate at any stage. The original questionnaires and anonymized data were obtained by the authors of this study.

\section{Consent for publication}

There is no identifiable information reported.

\section{Competing interests}

All authors declare that they don't have any financial or personal relationships or competing interests with other people or organizations. And all the authors have approved the final article.

\section{Author details}

'Department of Nursing, West China Hospital, Sichuan University, Chengdu, China. ${ }^{2}$ Department of Nursing, Southwest Medical University, Luzhou, China. ${ }^{3}$ Institute for Disaster Management and Reconstruction of Sichuan University and Hong Kong Polytechnic University, Chengdu, China. ${ }^{4}$ Swiss Paraplegic Research, Nottwil, Switzerland. ${ }^{5}$ Department of Health Sciences and Medicine, University of Lucerne, Lucerne, Switzerland. 'Department of Psychiatry, University of California San Francisco, San Francisco, CA, USA. ${ }^{7}$ Department of Anesthesiology, West China Hospital/West China School of Medicine, Sichuan University, Chengdu, China. ${ }^{8}$ Department of Nursing, Dujiangyan Second People's Hospital, Dujiangyan, China. ${ }^{9}$ Research Institute for Nursing Care, Information Engineering National Institute of Technology, Nara College, Nara, Japan. ${ }^{10}$ Center of Gerontology and Geriatrics, National Clinical Research Center of Geriatrics, West China Hospital, Sichuan University, No. 37 Guoxue Xiang, Chengdu 610041, Sichuan Province, China. ${ }^{11}$ Innovation Center for Nursing Research, West China School of Medicine/ West China Hospital, Sichuan University, No. 37 Guoxue Xiang, Chengdu 610041, Sichuan Province, China.

\section{Received: 4 March 2019 Accepted: 31 January 2020} Published online: 22 February 2020

\section{References}

1. Galea S, Nandi A, Vlahov D. The epidemiology of post-traumatic stress disorder after disasters. Epidemiol Rev. 2005;27(1):78-91.

2. Neria Y, Nandi A, Galea S. Post-traumatic stress disorder following disasters: a systematic review. Psychol Med. 2008;38(4):467-80.
3. Dai W, Chen L, Lai Z, Li Y, Wang J, Liu A. The incidence of post-traumatic stress disorder among survivors after earthquakes: a systematic review and meta-analysis. BMC Psychiatry. 2016;16(1):188-98.

4. Liang Y, Cheng J, Ruzek J, Liu Z. Posttraumatic stress disorder following the 2008 Wenchuan earthquake: A 10-year systematic review among highly exposed populations in China. J Affect Disord. 2019;243:327-39.

5. Kun $\mathrm{P}$, Tong $X$, Liu $Y$, Pei $X$, Luo $\mathrm{H}$. What are the determinants of posttraumatic stress disorder: age, gender, ethnicity or other? Evidence from 2008 Wenchuan earthquake. Public Health. 2013;127(7):644-52.

6. Howard A, Blakemore T, Bevis M. Older people as assets in disaster preparedness, response and recovery: lessons from regional Australia. Ageing Soc. 2017;37(03):517-36.

7. Glaesmer H, Gunzelmann T, Braehler E, Forstmeier S, Maercker A. Traumatic experiences and post-traumatic stress disorder among elderly Germans: results of a representative population-based survey. Int Psychogeriatr. 2010;22(4):661-70

8. Heqing $\mathrm{H}$, Yang $\mathrm{H}$, Buxin $\mathrm{H}$. The incidence rate and influencing factors of post-traumatic stress disorder among the elderly in different disaster areas after wenchuan earthquake. Chin J Gerontol. 2009;10:1275-7.

9. Zhang Z, Shi Z, Wang L, Liu M. Post-traumatic stress disorder, anxiety and depression among the elderly: a survey of the hard-hit areas a year after the Wenchuan earthquake. Stress Health. 2012;28(1):61-8.

10. Huimin F, Meiqin S, Xiang $Y$, et al. Investigation of PTSD and psychosomatic health of elderly cadres in chengdu two years after wenchuan earthquake. Sichuan Med J. 2012;09:1677-9.

11. Chen $\mathrm{G}$, Shen $\mathrm{H}$, Chen $\mathrm{G}$. A cross-sectional study on posttraumatic stress disorder among elderly Qiang citizens 3 years after the Wenchuan earthquake in China. Can J Psychiatr. 2012;57(9):547.

12. Ferry FR, Brady SE, Bunting BP, Murphy SD, Bolton D, O'Neill SM. The Economic Burden of PTSD in Northern Ireland. J Trauma Stress. 2015;28(3):191.

13. Frayne SM, Chiu W, lqbal S, Berg EA, Laungani KJ, Cronkite RC, Pavao J, Kimerling R. Medical Care Needs of Returning Veterans with PTSD: Their Other Burden. J Gen Intern Med. 2011;26(1):33-9.

14. Chao X, Aiwen L, Zengping W. Study on casualties of Dujiangyan City in Wenchuan earthquake. J Earthquake Eng Eng Vibration. 2012;01:182-8.

15. Horowitz M, Wilner N, Alvarez W. Impact of Event Scale- Measure of Subjective Stress. Psychosom Med. 1979;41(3):209-18.

16. Guoping $H$, Yalin $Z$, hui $X$, et al. The Chinese Version of The impact of event scale-revised of male offenders: Reliability and validity. Chin J Ment Health. 2006:20:28-31.

17. Qu ZY, Wang XH, Tian DH, Zhao Y, Zhang Q, He H, Zhang XL, Xu F, Guo SR. Posttraumatic stress disorder and depression among new mothers at 8 months later of the 2008 Sichuan earthquake in China. Arch Womens Ment Health. 2012;15(1):49-55.

18. Guo J, Liu C, Kong D, Solomon P, Fu M. The relationship between PTSD and Suicidality among Wenchuan Earthquake Survivors: The role of PTG and social support. J Affect Disord. 2018;235:90.

19. Guo J, He H, Fu MQ, Han ZQ, Qu ZY, Wang XH, Guan LD. Suicidality associated with PTSD, depression, and disaster recovery status among adult survivors 8 years after the 2008 Wenchuan earthquake in China. Psychiatry Res. 2017;253:383-90.

20. Guo J, Wang X, Yuan J, Zhang W, Tian D, Qu Z. The Symptoms of Posttraumatic Stress Disorder and Depression Among Adult Earthquake Survivors in China. J Nerv Ment Dis. 2015;203(6):469-72.

21. Liu ZY, Zeng ZQ, Xiang YJ, Hou FS, Li J, Li T, Hu XQ, Ping Y. A Crosssectional Study on Posttraumatic Impact Among Qiang Women in Maoxian County 1 Year After the Wenchuan Earthquake, China. ASIA-PAC J Public HE. 2012;24(1):21-7.

22. Qu Z, Tian D, Zhang Q, Wang X, He H, Zhang X, Huang L, Xu F. The impact of the catastrophic earthquake in China's Sichuan province on the mental health of pregnant women. J Affect Disord. 2012;136(1-2):117-23.

23. Chan CLW, Wang C, Qu Z, Lu BQ, Ran M, Ho AHY, Yuan Y, Zhang BQ, Wang X, Zhang $X$. Posttraumatic stress disorder symptoms among adult survivors of the 2008 Sichuan earthquake in China. J Trauma Stress. 2011;24(3):295-302.

24. Zhang $Y$, Ho SMY. Risk factors of posttraumatic stress disorder among survivors after the 512 Wenchuan earthquake in China. PLoS One. 2011;6(7):e22371.

25. Wang L, Zhang J, Shi Z, Zhou M, Huang D, Liu P. Confirmatory factor analysis of posttraumatic stress symptoms assessed by the Impact of Event Scale-Revised in Chinese earthquake victims: Examining factor structure and its stability across sex. J Anxiety Disord. 2011;25(3):369-75. 
26. Wang L, Zhang JX, Zhou MJ, Shi ZB, Liu P. Symptoms of posttraumatic stress disorder among medical workers in earthquake-stricken areas in southwest China. Psychol Rep. 2010;106(2):555-61.

27. Hu X, Cao X, Wang H, Chen Q, Liu M, Yamamoto A. Probable PostTraumatic Stress Disorder and Its Predictors in Disaster-Bereaved Survivors: A Longitudinal Study After the Sichuan Earthquake. Arch Psychiatr Nurs. 2016;30(2):192-7.

28. Schenk EJ, Yuan J, Martel LD, Shi G, Han K, Gao X. Risk factors for long-term post-traumatic stress disorder among medical rescue workers appointed to the 2008 Wenchuan earthquake response in China. Disasters. 2017;41(4): 788-802.

29. Qian C, Xuemei Z, Hu X. Investigation of suspected post-traumatic stress disorder in elderly survivors 6 months after the Lushan earthquake. J Peking Univ (medical edition). 2015;47(6):1046-9.

30. Pan X, Liu WZ, Deng GH, Liu TS, Yan J, Tang YX, Dong W, Cui Y, Xu M. Symptoms of posttraumatic stress disorder, depression, and anxiety among junior high school students in worst-hit areas 3 years after the Wenchuan earthquake in China. Asia-Pac J Public HE. 2015;27(2):1985-94.

31. Wu KK, Chan KS. The development of the Chinese version of Impact of Event Scale - Revised (CIES-R). Soc Psych Epid. 2003;38(2):94-8.

32. Guo SR, Xin ZQ, Geng LN, Liu-Na G. Reliability and validity of Chinese version of the impact of event scale-revised. Chin J Clin Psych. 2007;15(1): $15-7$.

33. Xu J, Wei Y. Social Support as a Moderator of the Relationship between Anxiety and Depression: An Empirical Study with Adult Survivors of Wenchuan Earthquake. PLoS One. 2013;8(10):e79045.

34. Weinstein ND, Lyon JE, Rothman AJ, Cuite CL. Preoccupation and affect as predictors of protective action following natural disaster. Brit J Health Psych. 2000;5(4):351-63.

35. Kiliç C, Ulusoy M. Psychological effects of the November 1999 earthquake in Turkey: an epidemiological study. Acta Psychiatr Scand. 2003;108(3):232-8.

36. Başoğlu M, Salcioğlu E, Livanou M. Traumatic stress responses in earthquake survivors in Turkey. J Nerv Ment Dis. 2002;15(4):269-76.

37. Zhang W, Duan G, Xu Q, Jia Z, Bai Z, Liu W, Pan X, Tian W. A Cross-sectional Study on Posttraumatic Stress Disorder and General Psychiatric Morbidity Among Adult Survivors 3 Years After the Wenchuan Earthquake, China. Asia Pac J Public He. 2015;27(8):860-70.

38. Dell'Osso L, Carmassi C, Massimetti G, Daneluzzo E, Di Tommaso S, Rossi A. Full and partial PTSD among young adult survivors 10months after the L'Aquila 2009 earthquake: Gender differences. J Affect Disord. 2011;131(1-3): 79-83.

39. Harris IA, Young JM, Rae H, Jalaludin BB, Solomon MJ. Predictors of posttraumatic stress disorder following major trauma. ANZ J Surg. 2008;78(7): 583-7.

40. Alonzo AA. The experience of chronic illness and post-traumatic stress disorder: the consequences of cumulative adversity. Soc Sci Med. 2000; 50(10):1475-84

41. Tang BH, Deng QY, Glik D, Dong JQ, Zhang LL. A Meta-Analysis of Risk Factors for Post-Traumatic Stress Disorder (PTSD) in Adults and Children after Earthquakes. Int J Env Res Pub HE. 2017;14(12):1537-56.

42. Koyama S, Aida J, Kawachi I, Kondo N, Subramanian SV, Ito K, Kobashi G, Masuno K, Kondo K, Osaka K. Social Support Improves Mental Health among the Victims Relocated to Temporary Housing following the Great East Japan Earthquake and Tsunami. Tohoku J Exp Med. 2014;234(3):241-7.

43. Yokoyama Y, Otsuka K, Kawakami N, Kobayashi S, Ogawa A, Tannno K, Onoda T, Yaegashi Y, Sakata K. Mental Health and Related Factors after the Great East Japan Earthquake and Tsunami. PLoS One. 2014;9(7):1-10

44. Xu JP, Deng YF. Mental health service use one year after China 5.12 earthquake: Relationship with post-traumatic stress disorder among survivors. J Ment Health. 2013;22(6):509-18.

45. Xu L, Gangshu D. Summary and inspiration of post-wenchuan earthquake reconstruction. J Univ Electron Sci Technol (social science edition). 2010;12(5): $16-9$.

46. Guo J, He H, Qu ZY, Wang XH, Liu CB. Post-traumatic stress disorder and depression among adult survivors 8 years after the 2008 Wenchuan earthquake in China. J Affect Disord. 2017;210:27-34.

47. Guo J, Wu P, Tian DH, Wang XH, Zhang WJ, Zhang XL, Qu ZY. Posttraumatic Stress Disorder among adult survivors of the Wenchuan Earthquake in China: A repeated cross-sectional study. J Anxiety Disord. 2014;28(1):75-82.
48. World Health Organization. World report on ageing and health.2015. Available online at: https://www.who.int/ageing/publications/worldreport-2015/en/

49. Reinhardt JD, Zhang X, Van Dyke C, Zhao Z, Zhao M, Li H. Post-traumatic Stress Disorder in a Population of 2008 Wenchuan Earthquake Survivors with Disabilities: The Role of Environmental Barriers. Disabil Rehabil (in press). 2020;1-9. https://doi.org/10.1080/09638288.2020.1714756.

\section{Publisher's Note}

Springer Nature remains neutral with regard to jurisdictional claims in published maps and institutional affiliations.
Ready to submit your research? Choose BMC and benefit from:

- fast, convenient online submission

- thorough peer review by experienced researchers in your field

- rapid publication on acceptance

- support for research data, including large and complex data types

- gold Open Access which fosters wider collaboration and increased citations

- maximum visibility for your research: over $100 \mathrm{M}$ website views per year

At BMC, research is always in progress.

Learn more biomedcentral.com/submissions 